C. Held • A. Kandelbauer • M. Schroeder •

A. Cavaco-Paulo • G. M. Guebitz

\title{
Biotransformation of phenolics with laccase containing bacterial spores
}

Received: 5 May 2005 / Accepted: 9 August 2005 / Published online: 22 October 2005

(C) Springer-Verlag 2005

\begin{abstract}
Treatment of effluents containing phenols such as textile dyes with fungal laccases is usually limited to the acid to neutral $\mathrm{pH}$ range and moderate temperatures. Here we demonstrate for the first time that spore-bound laccases which are stable at high temperatures and $\mathrm{pH}$ values can be used for phenolic dye decolorisation. Laccase containing spores from Bacillus SF were immobilized on alumina pellets. Both immobilized and free spores were able to completely decolorize the common textile dyes Mordant Black 9, Mordant Brown 96/Mordant Brown 15, and Acid Blue 74 within 90 min of incubation time and decolorized solutions were successfully used in re-dyeing.
\end{abstract}

Keywords Bacillus $\cdot$ Spores $\cdot$ Biodegradation of phenolics $\cdot$ Effluent treatment

\section{Introduction}

Laccases (benzenediol:oxygen oxidoreductase, EC 1.10.3.2) have found several applications in enzyme remediation. Laccases as well as immobilized laccases have been used for the treatment of phenolic effluents, PAHs and PCBs. The enzymes render phenolic compounds less toxic via degradation or polymerization reactions and/or crosscoupling of pollutant phenols with naturally occurring phenols (Bohmer et al. 1998; D'Annibale et al. 2000; Ullah et al. 2000). Besides microbial processes (Fischer-Colbrie et al. 2005), laccases have also a potential for the decolorization of textile dyes (Kandelbauer and Guebitz 2005).

C. Held · A. Kandelbauer · M. Schroeder · G. M. Guebitz ( $\triangle)$ Department of Environmental Biotechnology, Graz University of Technology,

Petersgasse 12,

8010 Graz, Austria

e-mail: guebitz@tugraz.at

Tel.: +43-316-873-8312

Fax: +43-316-873-8815

A. Cavaco-Paulo

Department of Textile Engineering, University of Minho, 4800 Guimaraes, Brazil
Laccases catalyze the removal of a hydrogen atom from the hydroxyl group of ortho and para-substituted monophenolic and poly-phenolic substrates and from aromatic amines by one-electron abstraction, to form free radicals, capable of undergoing further depolymerization, repolymerization, demethylation or quinone formation.

For dye decolorization, the laccases from a number of fungi such as Sclerotium rolfsii, Trametes modesta, T. hirsuta, T. versicolor, Pleurotus pulmonarius among others have been investigated (Kandelbauer and Guebitz 2005). However, the potential of bacterial laccases for this purpose has not been assessed so far. In contrast to fungal laccases which are known for many years, laccase activity in bacteria has only been described in 1993 for Azospirillum lipoferum and has been characterized later in more detail (Diamantidis et al. 2000). Interestingly, the spore coat protein CotA of Bacillus subtilis was identified as laccase (Hullo et al. 2001). Since spores serve microorganisms to survive drastic conditions, spore coat enzymes might also withstand high temperatures or extreme $\mathrm{pH}$ values which would be advantageous for industrial applications.

It has previously been shown that residual enzyme after enzymatic decolorization of dyeing effluents can restrict the reuse of water (Abadulla et al. 2000). Enzyme protein can adsorb to fabrics and thus lead to unwanted color differences in dyeing with enzymatically decolorized effluents. Therefore, for continuous applications in dye decolorization and also in other applications immobilization of laccases is required and several successful examples have been reported (Abadulla et al. 2000; Kandelbauer et al. 2004).

In a previous study higher decolorization rates were reported with an immobilized laccase from the white-rot fungus Trametes modesta when compared to the free enzyme. Despite the promising efficiency of dye decolorization in general, no decolorization activity at all was observed at $\mathrm{pH}$ values higher than $\mathrm{pH} 7$ (Kandelbauer et al. 2004). This limits the industrial potential since many dyeing processes (e.g., cotton) are performed in the alkaline $\mathrm{pH}$ range. Alternatively, spore laccases which are also active in the alkaline $\mathrm{pH}$ range could be used for dye decolorization without liberation from spores allowing simple immobilization of 
spores or application in membrane reactors. In this study, we report for the first time the use of a spore laccase from Bacillus SF for dye decolorization.

\section{Experimental}

\section{Cultivation of Bacillus SF}

Bacillus SF was isolated as described previously (Gudelj et al. 2001). Cultures were grown on Caso-agar (Merck) plates $\mathrm{pH}$ adjusted with $\mathrm{NaOH}$ to 8.5 for 2 days at $55^{\circ} \mathrm{C}$ and thereafter stored at $4{ }^{\circ} \mathrm{C}$. The medium for liquid cultivation of Bacillus SF consisted of two different solutions which were combined after autoclaving. Solution A $\left(\mathrm{g} \mathrm{l}^{-1}\right): 3.5$ $\mathrm{KH}_{2} \mathrm{PO}_{4}, 4.98 \mathrm{NaHPO}_{4} \cdot 2 \mathrm{H}_{2} \mathrm{O}, 2.5\left(\mathrm{NH}_{4}\right)_{2} \mathrm{SO}_{4}, 10$ yeast extract, 10 peptone from casein $\mathrm{L}, 60 \mathrm{ml} 1 \mathrm{M} \mathrm{NaOH}$, Solution B $\left(\mathrm{g} \mathrm{l}^{-1}\right)$ : $4.5 \mathrm{MgSO}_{4} \cdot 7 \mathrm{H}_{2} \mathrm{O}, 0.2 \mathrm{MnSO}_{4} \cdot \mathrm{H}_{2} \mathrm{O}$ $\mathrm{l}^{-1}, 100 \mathrm{ml}$ iron citrate $\left(8,9 \mathrm{~g} \mathrm{l}^{-1}\right), 25 \mathrm{ml}$ trace element solution SL6 $1^{-1}, 10 \mathrm{ml} 1 \mathrm{M} \mathrm{NaOH}^{-1}$. The medium for the induction of sporulation of Bacillus SF consisted of $\left(\mathrm{g} \mathrm{l}^{-1}\right)$ 8 nutrient broth (Merck), $1 \mathrm{KCl}, 0.25 \mathrm{MgSO}_{4} \cdot 7 \mathrm{H}_{2} \mathrm{O}$, and after autoclaving $\left(121^{\circ} \mathrm{C}, 30 \mathrm{~min}\right)$ sterile $1 \mathrm{ml} \mathrm{l}^{-1}$ of the following solutions was added $1 \mathrm{M} \mathrm{Ca}\left(\mathrm{NO}_{3}\right)_{2} \cdot 4 \mathrm{H}_{2} \mathrm{O}, 0.01 \mathrm{M}$ $\mathrm{MnCL}_{2}, 0.001 \mathrm{M} \mathrm{FeSO}_{4}$, and $0.5 \mathrm{ml}$ of $1 \mathrm{M} \mathrm{NaOH}$ solution. The 11 baffled Erlenmeyer flasks containing $250 \mathrm{ml}$ of the above medium were inoculated with Bacillus SF actively growing on agar plates and incubated at $55^{\circ} \mathrm{C}$ on a rotary shaker $(130 \mathrm{rpm})$ for 3 days and then $5 \mathrm{ml} \mathrm{l}^{-1}$ were transferred to the sporulation medium.

\section{Immobilization of the spores}

Alumina pellets (Sigma) were silanized twice at $50^{\circ} \mathrm{C}$ for $24 \mathrm{~h}$ in a $3 \%(\mathrm{v} / \mathrm{v})$ solution of aminopropyl triethoxy silane (Sigma) in acetone. The silanized pellets were washed with distilled water and immersed in $2.5 \%(\mathrm{v} / \mathrm{v})$ aqueous glutardialdehyde solution (Sigma) for $2 \mathrm{~h}$ at $20^{\circ} \mathrm{C}$. Thereafter, the pellets were incubated with $60 \mathrm{mg}$ spores $1^{-1}$ for $5 \mathrm{~h}$ at $20^{\circ} \mathrm{C}$. The immobilized spore pellets were washed with buffer ( $\mathrm{pH} 8.5)$ and kept refrigerated until further use. Effective laccase activity of solution was determined before and after immobilization.

\section{Laccase activity}

Before its usage in decolorization, the effective activities of the laccase and laccase activity of spore dispersions were determined using the oxidation of 2,6-dimethoxyphenol (DMP). The reaction mixture contained $50 \mathrm{mM}$ sodium malonate (pH 4.5), $1 \mathrm{mM}$ DMP, $1 \mathrm{mM} \mathrm{MnSO} 4$, and $700 \mu \mathrm{l}$ sample in a total of $1 \mathrm{ml}$. The formation of $2,2^{\prime}, 6,6^{\prime}-$ dimethoxydiphenoquinone at $30^{\circ} \mathrm{C}$ was followed spectrophotometrically at $468 \mathrm{~nm}$ and apparent laccase activity was calculated from the molar extinction coefficient $\varepsilon=49.6 \mathrm{mM}^{-1} \mathrm{~cm}^{-1}$.
Isolation of the laccase from the spores

Culture $(40 \mathrm{ml})$ were harvested through centrifugation at $9000 \times g$ for $30 \mathrm{~min}$. The supernatant was withdrawn and the pellet was washed twice through resuspension in $10 \mathrm{ml}$ of deionized water and centrifugation $(9000 \times g, 15 \mathrm{~min})$. After a final centrifugation at $16000 \times g$ for $20 \mathrm{~min}$ cells (spores) were resuspended in an equal volume of a solution containing $0.1 \mathrm{M} \mathrm{NaOH}, 8.0 \mathrm{M}$ urea, $1 \%$ sodiumdodecylsulfate. Cells were incubated for $15 \mathrm{~min}$ at $25^{\circ} \mathrm{C}$ and subsequently centrifuged at $16000 \times g$ for $20 \mathrm{~min}$. The supernatant was filtrated through $0.22 \mu \mathrm{m}$ membrane filter (Osmonics Inc., Germany) at 2 bar positive pressure. Sodiumdodecylsulfate (SDS) was removed from the crude enzyme preparation through precipitation with an equal amount of $0.5 \mathrm{M}$ potassium acetate buffer $\mathrm{pH} 5$ as potassium dodecylsulfate (PDS). After incubation for $15 \mathrm{~min}$ at $25^{\circ} \mathrm{C}$ PDS precipitate was removed through centrifugation at $16000 \times g$ for $20 \mathrm{~min}$ and filtration through $0.22 \mu \mathrm{m}$ membrane filter. Urea was removed through centrifugation with vivaspin (Satorius AG, Germany) centrifugal concentrators molecular cutoff $5 \mathrm{kDa}$ and exchanging the buffer with $0.2 \mathrm{M} \mathrm{N}, \mathrm{N}, \mathrm{N}$-tris(hydroxymethyl) aminomethane hydrochloride buffer $\mathrm{pH} 8.5$.

\section{Temperature and pH-stabilities}

The thermal stability of the laccase was examined by preincubation in $10 \mathrm{mM}$ phosphate buffer $\mathrm{pH} 8.0$ of free and immobilized spores at various temperatures and measurement of remaining activity with the assay described above. The $\mathrm{pH}$-stabilities were determined similarly incubating free and immobilized spores at $25^{\circ} \mathrm{C}$ in different buffers ranging from $\mathrm{pH} 5.0$ to 9.5 .

\section{Dye decolorization experiments}

For decolorization experiments, the commercial textile dyes Diamond Black PV 200 (CI Mordant Black 9 (DBPV 200)), Diamond Fast Brown (CI Mordant Brown 96/CI Mordant Brown 15 (DFB)) kindly donated from DyeStar and Indigo Carmine (IC) (Acros) were used. Aqueous solutions containing $50 \mathrm{mg} \mathrm{l}^{-1}$ dye treated with $5 \mathrm{~g} \mathrm{l}^{-1}$ spores or $7 \mathrm{~g}^{-1}$ immobilized spores at $60^{\circ} \mathrm{C}$ for $90 \mathrm{~min}$. Samples were withdrawn every $5 \mathrm{~min}$ and analyzed by UV/Vis spectroscopy using a U-2001 Hitachi spectrophotometer in the spectral range of $240-800 \mathrm{~nm}$ with a scan speed of $1200 \mathrm{~nm} \mathrm{~min}{ }^{-1}$. To account for the effects of temperature and $\mathrm{pH}$, controls were performed without spores while the typical laccase inhibitor $\mathrm{NaF}(1 \mathrm{mM})$ was added to account for possible adsorption effects.

\section{Dyeing experiments}

Bleached cotton fabrics $(10 \times 10 \mathrm{~cm})$ were dyed with either CI Reactive Orange 70 or CI Reactive Blue in liquors containing enzymatically decolorized dyes and $20 \mathrm{~g} \mathrm{l}^{-1}$ 
$\mathrm{Na}_{2} \mathrm{CO}_{3}$ and $60 \mathrm{~g} \mathrm{l}^{-1} \mathrm{Na}_{2} \mathrm{SO}_{4}$. An Ahiba Spectradye dyeing apparatus (Datacolor International, Luzern, Switzerland) was used at a liquor to good ratio of 20:1 (40 rpm, step 1: temperature was raised from 20 to $60^{\circ} \mathrm{C}$ in $20 \mathrm{~min}$; step 2: $\left.60^{\circ} \mathrm{C}, 60 \mathrm{~min}\right)$. Dye load was either low $(0.5 \%)$ or high $(3 \%)$ with respect to the dry mass of the fabric. Dyed fabrics were washed at the same liquor ratio with the nonionic detergent Hostapal CV $\left(1 \mathrm{~g} \mathrm{l}^{-1}\right)$ for $30 \mathrm{~min}$ at $90^{\circ} \mathrm{C}$ to remove the unfixed dye. Diode array spectrums (TIDAS instrument from $\mathrm{J}$ and $\mathrm{M}$, Aalen, Germany) of dyes both in standard dye baths and in dye baths containing enzymatically decolorized dyes were recorded.

Color differences of the dyed fabrics were determined using a reflectance measuring apparatus (Spectraflash 600 from Datacolor, Luzern, Switzerland) according to the CIELAB color difference concept at standard illuminant D65 (LAV/Spec. Excl., d/8, D65/10 ${ }^{\circ}$ ) with a color tolerance interval of 1 CIELAB unit. Color deviation was also quantified by calculating the $K / S$ values from reflectance measurements on the dyed fabrics.

\section{Results and discussion}

Laccase activity

The activity of the Bacillus SF spore bound laccase was dependent on the age of the spores. Maximum activity was achieved after 9 days of growth. Thereafter, activity remained constant within the observed time of 14 days. Laccase activities of spores were $0.64 \mathrm{U} \mathrm{mg}^{-1}$ dry weight of spores. The effective laccase activity of the immobilized spores was $0.48 \mathrm{U} \mathrm{mg}^{-1}$ (based on the amount of spores immobilized) indicating that immobilization partially inactivated the laccase and/or restricted the access of the substrate to the enzyme.

Several procedures for the isolation of the laccase from spores were compared (data not shown) and only a drastic treatment led to release of active laccase (6\%). Most likely this low activity recovery is due to incomplete re-naturation of the enzyme.

\section{Temperature stabilities}

The temperature stability (half life times $t_{1 / 2}$ ) of the free Bacillus SF laccase liberated from spores was only $5 \mathrm{~min}$ at $60^{\circ} \mathrm{C}$ and $\mathrm{pH}$ 8.0. In contrast, the observed half life times of laccase activity of Bacillus SF spores revealed high temperature stabilities of $66 \mathrm{~h}$ at $60^{\circ} \mathrm{C}$ and $\mathrm{pH}$ 8.0. These values are about six and 20 times higher than stabilities of fungal laccases reported previously for this temperature and optimum $\mathrm{pH}$ values of the individual enzymes $(11.5 \mathrm{~h}$, Abadulla et al. 2000 and $3 \mathrm{~h}$, D'Annibale et al. 2000). At $80^{\circ} \mathrm{C}$ the half life was still $30 \mathrm{~min}$. Immobilization of the Bacillus SF spores onto alumina pellets slightly increased the half life times from 66 to $80 \mathrm{~h}$ at $60^{\circ} \mathrm{C}$. Similarly, increased temperature stabilities have been reported previously for fungal laccases. (Abadulla et al. 2000; D’Annibale et al. 2000).

\section{$\mathrm{pH}$ stabilities}

The $\mathrm{pH}$ half life time of the free Bacillus SF laccase was $48 \mathrm{~h}$ at $\mathrm{pH}$ 8.5. However, the laccase activity of Bacillus SF spores showed higher stabilities over a broad $\mathrm{pH}$ range. Within a $\mathrm{pH}$ range from 5.0 to 7.0 the half life was more than $120 \mathrm{~h}$ compared to $13 \mathrm{~h}$ previously measured for a laccase from Trametes hirsuta (Abadulla et al. 2000). In contrast to fungal laccases, laccase activity of Bacillus SF spores showed a very high stability at alkaline $\mathrm{pH}$ values $\left(t_{1 / 2}=67 \mathrm{~h}\right.$ at $\left.\mathrm{pH} 9.5\right)$. These observed half life times indicate a high potential for industrial processes like dye decolorization, detoxification, and transformation of phenolic and other compounds where high temperatures and $\mathrm{pH}$ values are common. Previously, an intracellular catalase-peroxide from this Bacillus SF has been described which also showed high stabilities at alkaline $\mathrm{pH}$ and high temperatures (Gudelj et al. 2001).

\section{Dye decolorization}

Based on the high stability of laccase activity of Bacillus SF spores compared to the liberated enzyme, only spores and immobilized spores were investigated for dye decolorization. The spore laccases as well as the spores immobilized on inorganic carrier material were used for the decolorization of the common textile dyes DBPV 200 (CI Mordant Black 9), DFB (CI Mordant Brown 96/CI Mordant Brown 15) and IC (CI Acid Blue 74) in order to demonstrate their potential for the treatment of process waters contaminated with excess dyestuff. Both types of spore preparations proved to be very efficient in the complete removal of color within less than 90 min of incubation time.

Decolorization rates depended upon dye structure. DBPV 200, DFB, and IC were almost completely decolorized after 35, 50, and 65 min, respectively (Fig. 1). A similar trend was found earlier when an immobilized laccase from the white-rot fungus Trametes modesta was used to treat the same dyes (Kandelbauer et al. 2004). Although the optimum decolorization rates were generally higher with the immobilized fungal laccase, they were strongly dependent on acidic conditions and no decolorization activity at all was observed at $\mathrm{pH}$ values higher than $\mathrm{pH} 7$. In contrast, when using the bacterial spore preparations, decolorization was achieved at $\mathrm{pH}$ 9. Furthermore, in previous experiments with fungal laccases, the optimum temperature for dye decolorization was never above $40^{\circ} \mathrm{C}$ whereas in the present experiments the best results were found at $60^{\circ} \mathrm{C}$. No significant decolorization was seen when the laccase inhibitor $\mathrm{NaF}$ was present in the incubation mixtures indicating that adsorption did not contribute to decolorization.

Our results indicate access of substrates to the outer spore coat protein of Bacillus sp. displaying laccase activity does not seem to be sterically limited. This is in agreement with previous data for immobilized fungal laccases. Consequently, in different general decolorization rates of structurally different dyes are rather due to presence of different electron withdrawing of electron donating substituents on 


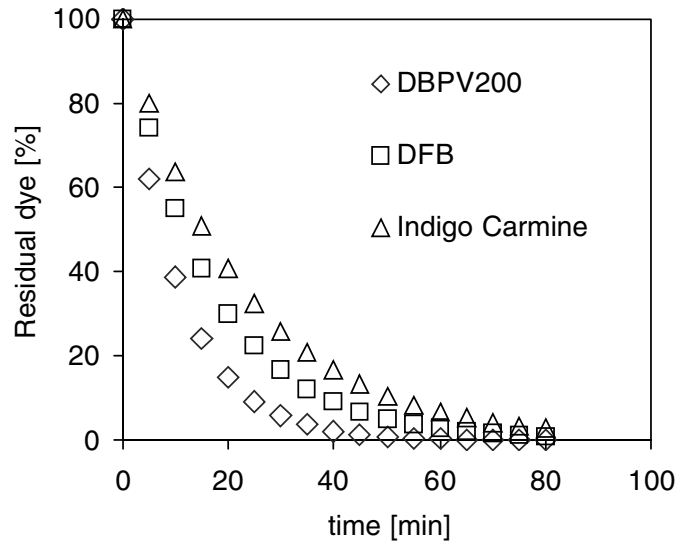

Fig. 1 Decolorization of textile dyes with immobilized spore-bound laccase from Bacillus SF

the aromatic rings than due to sterical effects (Kandelbauer et al. 2004). In the next section it will be shown that the spore-treated dye solutions can be re-used for dyeing operations.

\section{Cotton dyeing}

Re-using the laccase-treated effluent in the dyeing process we have found previously that enzyme protein obviously strongly interfered with the dyeing process while promising results were obtained with the immobilized laccases (Abadulla et al. 2000). This was indicated by dE* values of the dyed fabrics below 1.1, which is acceptable to the industry. Shifts in dye absorption maximum in solution could be caused by binding of auxochromes to the dye molecules. Alternatively, degradation products and/or protein could cause aggregation of dye molecules preventing the dye uptake to the fabric, which would cause larger color fail. Thus, immobilization of enzymes seems to be strictly required in order to allow reuse of enzyme-treated effluents.

Decolorized solutions of the three commercial dyes DBPV 200, DFB, and IC were used for the dyeing of bleached cotton with reactive dyes. Results are shown in Fig. 2. Even with low dye concentrations, no significant color differences between fabrics dyed in baths prepared with water or enzyme-treated dye solutions were seen. Only in the case of enzyme-treated solutions of IC high dye concentrations were necessary in a second dyeing step to reach acceptable $\mathrm{dE} *$ differences of the dyed fabrics below 1.1.

\section{Conclusion}

In this study we have shown for the first time that spores from Bacillus SF with laccase activity can be used for continuous decolorization of dyes when immobilized on alumina carriers. Despite some loss of laccase activity due to the immobilization procedure both $\mathrm{pH}$ and temperature stabilities of laccase activity of the immobilized spores were higher than those of the free spores. Dye solutions treated with spore laccase can be used for the preparation of new dyeing baths leading to acceptable color differences of around $1 \mathrm{dE}$.

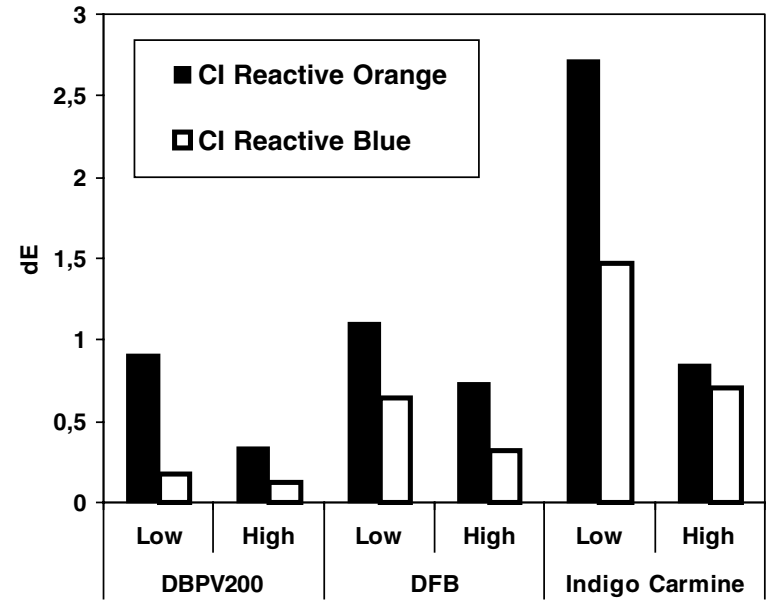

Fig. 2 Color difference (dE) between cotton fabrics dyed with Reactive Orange 70 or Reactive blue 214 (high and low concentration) either in water or decolorized dye solutions. Dye solutions containing the textiles dyes DBPV 200, DFB, and IC were decolorized with immobilized spore laccase from Bacillus SF

Acknowledgements This study was supported by the European Project BIOEFFTEX and the Competence Centre Applied Biocatalysis

\section{References}

Abadulla E, Tzanov T, Costa S, Robra KH, Cavaco-Paulo A, Gübitz GM (2000) Decolorization and detoxification of textile dyes with a laccase from Trametes hirsuta. Appl Environ Microbiol 66:3357-3362

Bohmer S, Messner K, Srebotnik E (1998) Oxidation of phenanthrene by a fungal laccase in the presence of 1-hydroxybenzotriazole and unsaturated lipids. Biochem Biophs Res Commun 244:233-238

D'Annibale A, Stazi SR, Vinciguerra V, Sermanni GG (2000) Oxirane-immobilized Lentinula edodes laccase: stability and phenolics removal efficiency in olive mill wastewater. $\mathbf{J}$ Biotechnol 77:265-273

Diamantidis G, Effosse A, Potier P, Bally R (2000) Purification and characterization of the first bacterial laccase in the rhizospheric bacterium Azospirillum lipoferum. Soil Biol Biochem 32:919-927

Fischer-Colbrie G, Maier J, Robra K-H, Gübitz GM (2005) Degradation of the indigo carmine dye by an anaerobic mixed population. In: Lichtfouse E, Dudd S, Robert D (eds) Environmental chemistry. Springer-Verlag, Heidelberg, pp 289-294

Gudelj M, Fruhwirth G, Paar A, Lottspeich F, Robra KH, CavacoPaulo A, Gübitz GM (2001) A catalase-peroxidase from a newly isolated thermoalkalophilic Bacillus sp. with potential for the treatment of textile bleaching effluents. Extremophiles 5:423-429

Hullo MF, Moszer I, Danchin A, Martin-Verstraete I (2001) CotA of Bacillus subtilis is a copper-dependent laccase. J Bacteriol 183:5426-5430

Kandelbauer A, Guebitz GM (2005) Bioremediation for the decolorization of textile dyes, a review. In: Lichtfouse E, Schwarzbauer J, Robert D (eds) Environmental chemistry. Springer-Verlag, Heidelberg, pp 269-288

Kandelbauer A, Maute O, Kessler RW, Erlacher A, Gubitz GM (2004) Study of dye decolorization in an immobilized laccase enzyme-reactor using online spectroscopy. Biotechnol Bioeng 87:552-563

Ullah MA, Bedford CT, Evans CS (2000) Reactions of pentachlorophenol with laccase from Coriolus versicolor. Appl Microbiol Biotechnol 53:230-234 